\title{
Factors Affecting the Distribution of Copulatory Plugs in Rhesus Monkeys (Macaca mulatta) on Cayo Santiago
}

\author{
J. Danzy ${ }^{\mathrm{a}} \quad$ V. Gutierrez ${ }^{\mathrm{b}} \quad$ J. Pampush ${ }^{\mathrm{a}} \quad$ B. Campbell ${ }^{\mathrm{a}}$
}

a Department of Anthropology, University of Wisconsin-Milwaukee, Milwaukee, Wisc., and ${ }^{\mathrm{b}}$ Department of Sociology-Anthropology, New Mexico State University, Las Cruces, N. Mex., USA

\section{Key Words}

Rhesus macaques - Copulatory plugs • Colouration · Sperm competition •

Sexual skin

\begin{abstract}
Although the proximate mechanisms behind the formation of copulatory plugs are well understood, their distribution and function among primates remain largely unstudied. During a study of female rhesus macaque (Macaca mulatta) mating behaviour on Cayo Santiago, we examined the pattern of the distribution of visible copulatory plugs among females and their potential relationship to female reproductive traits and sexual skin colouration. Our results indicate that non-pregnant females were observed more frequently with visible copulatory plugs than were pregnant females. Female parity status, age and rank were unrelated to copulatory plug observation. Genital colouration components were higher among females observed with copulatory plugs. We suggest that although copulatory plugs are generally thought of in terms of male physiology, plug observation may also be affected by female reproductive status.
\end{abstract}

Copyright $\odot 2009$ S. Karger AG, Basel

\section{Introduction}

Copulatory plugs are found among taxonomically diverse groups including arthropods, lizards, snakes, rodents and primates [Poiani, 2006]. Although the evolutionary and physiological mechanisms are not fully understood, copulatory plugs are thought to facilitate the reproductive success of particular males [Dixson and Anderson, 2002] and may have evolved in response to intersexual conflict [Hernandez-Lopez et al., 2008]. Previous research on copulatory plugs has traditionally focused on the facilitation of fertilization by preventing sperm leakage, slowing sperm

\section{KARGER}

Fax +4161306 1234

E-Mail karger@karger.ch

www.karger.com
(C) 2009 S. Karger AG, Basel

Accessible online at: www.karger.com/fpr
Jennifer Danzy, Department of Anthropology

University of Wisconsin-Milwaukee

PO Box 413, Milwaukee, WI 53201 (USA)

Tel. +1 414229 4175, Fax +1 4142295848

E-Mail jldanzy@uwm.edu 


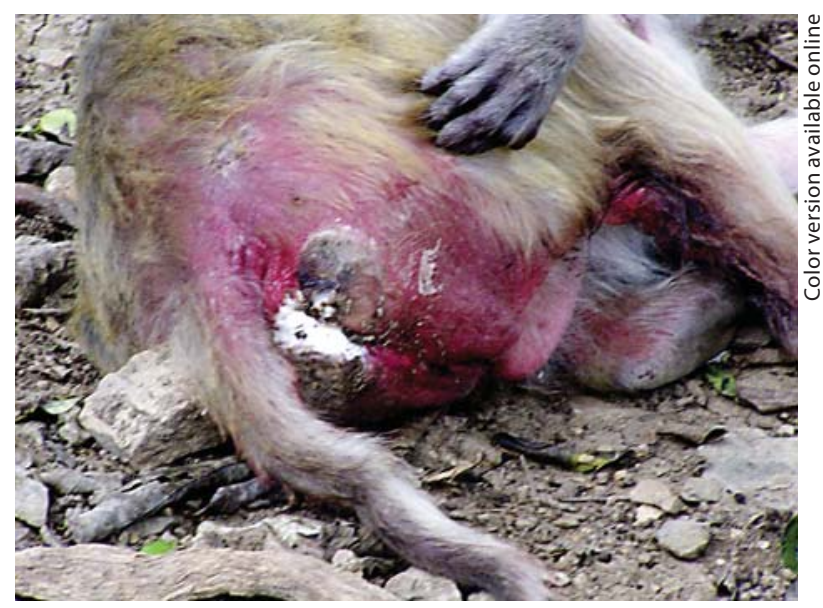

Fig. 1. Female (I56) with a copulatory plug.

release and helping sperm to reach the cervix; other hypotheses have focused on male-male competition and reproductive strategies, suggesting that copulatory plugs may serve as an obstacle for subsequent males [for a review, see Voss, 1979].

Dixson and Anderson [2002] reviewed the evidence for seminal coagulation and copulatory plugs in primates; the authors rate the extent of plug formation on a scale of 1-4. Categories 1 and 2 are those species in which semen remains completely fluid or semi-fluid, while categories 3 and 4 are distinguished by a seminal coagulate or a dense copulatory plug. Dixson and Anderson [2002] classify rhesus monkeys in category 3 because their ejaculate forms a seminal coagulate but not a true, dense copulatory plug like those found among some lemurs. According to Dixson and Anderson [2002], a softer seminal coagulate may contribute more to the gradual release of sperm than a true copulatory plug, thus level 3 copulatory plugs are still important in terms of the sperm competition hypothesis. The authors suggest that both seminal coagulates and true copulatory plugs are more frequently found in those species where females have multiple partners during oestrus. Monogamous species do not display plugs, while plugs are more frequently observed among multimale-multifemale or dispersed species.

Rhesus monkeys live in multimale-multifemale societies with promiscuous mating. Rhesus males have several reproductive strategies [Berard, 1999] and also have large testes for their body size, indicating the importance of sperm production as a postcopulatory strategy [Harcourt et al., 1981; Muehlenbein et al., 2002]. Although Dixson and Anderson [2002] suggest that rhesus monkeys have a softer seminal coagulate instead of a true plug, we observed (fig. 1,2) that plugs occasionally form a dense, rubbery solid [Settlage and Hendrickx, 1974] that is molded to the contours of the female reproductive tract. We will, therefore, refer to them as copulatory plugs throughout the paper.

Our study is unique in that it examines the distribution pattern of copulatory plugs among females. We examined the frequency and distribution of visible copula- 


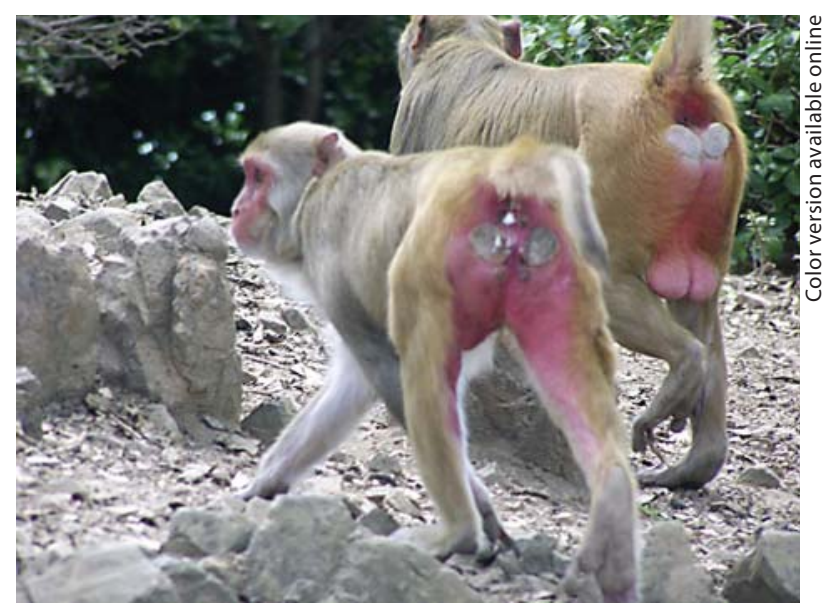

Fig. 2. Female (Z82) with an adult male after mating and receiving a copulatory plug.

tory plugs among female rhesus monkeys on Cayo Santiago during a mating season to determine if the rate of visible copulatory plugs was related to female reproductive traits and/or changes in sexual skin colouration. The specific goals of this project were to examine two research questions: (1) Is there a relationship between visible copulatory plugs and female traits such as pregnancy status, parity status, age and dominance rank? (2) Is there a relationship between the rate of visible copulatory plugs and genital colouration?

\section{Materials and Methods}

This project was part of a larger study of female rhesus macaque mating behaviour and colouration. The project took place on Cayo Santiago; data were collected between May and August 2006, during the mating season [for site details, see Carpenter, 1942; Altmann, 1962; Rawlins and Kessler, 1986]. Data were collected from group S, which was composed of 76 members. All group members were easily identifiable to observers (J.D. and V.G.) for data collection; the interobserver reliability rate of behaviours recorded was $90 \%$ before behavioural data were collected. Data were collected as part of a larger study examining the relationships between female colour, faecal glucocorticoid levels, behaviour and life history [Danzy, 2007].

For this study, three types of data were collected: focal behavioural observations (focal animal and ad libitum [Altmann, 1974]), digital photographs and female traits (collected from the Cayo Santiago census database); all data were collected by observation without direct contact with the subjects. Focal-animal data and colour data were collected for 10 randomly chosen multiparous females. Ad libitum mating, copulatory plug and pregnancy data were also collected for all group females, including 6 adolescent, non-parous females and 17 parous females (table 1).

Reproductive status (mating vs. non-mating) was determined on the basis of daily behavioural and ad libitum observations of each female in the group. A mating day was defined as one when a female was observed receiving a mount with intromission and/or observed with a copulatory plug. Receiving a copulatory plug was also noted daily for each female, as part of a subset of her mating days. Each female mating day was sorted as either resulting in a copula- 
Table 1. Summary of copulatory plug data

\begin{tabular}{|c|c|c|c|c|c|}
\hline $\begin{array}{l}\text { Animal } \\
\text { ID }\end{array}$ & $\begin{array}{l}\text { Age } \\
\text { months }\end{array}$ & Rank & $\begin{array}{l}\text { Number of } \\
\text { plugs observed }\end{array}$ & $\begin{array}{l}\text { Number of } \\
\text { matings observed }\end{array}$ & $\begin{array}{l}\text { Rate of visible } \\
\text { copulatory plugs }\end{array}$ \\
\hline $38 \mathrm{Z}$ & 24 & 2 & 3 & 4 & 0.75 \\
\hline $57 \mathrm{~T}$ & 36 & 16 & 5 & 6 & 0.83 \\
\hline $03 \mathrm{~S}$ & 48 & 5 & 0 & 2 & 0.00 \\
\hline 97R & 48 & 8 & 3 & 5 & 0.60 \\
\hline $45 \mathrm{R}$ & 48 & 17 & 1 & 1 & 1.00 \\
\hline $51 R$ & 48 & 22 & 0 & 1 & 0.00 \\
\hline $88 \mathrm{~N}$ & 75 & 19 & 7 & 10 & 0.70 \\
\hline $89 \mathrm{~L}$ & 77 & 12 & 2 & 6 & 0.33 \\
\hline $82 \mathrm{H}$ & 100 & 23 & 0 & 1 & 0.00 \\
\hline $81 \mathrm{I}$ & 113 & 15 & 4 & 6 & 0.66 \\
\hline $30 \mathrm{~F}$ & 126 & 10 & 4 & 12 & 0.33 \\
\hline $36 \mathrm{D}$ & 136 & 13 & 4 & 4 & 1.00 \\
\hline $42 \mathrm{~A}$ & 162 & 3 & 2 & 6 & 0.33 \\
\hline Z99 & 172 & 7 & 5 & 5 & 1.00 \\
\hline $06 \mathrm{~A}$ & 172 & 14 & 0 & 5 & 0.00 \\
\hline Z82 & 174 & 20 & 19 & 25 & 0.76 \\
\hline X60 & 185 & 18 & 2 & 3 & 0.66 \\
\hline T84 & 193 & 9 & 3 & 9 & 0.33 \\
\hline T83 & 195 & 21 & 8 & 15 & 0.53 \\
\hline $\mathrm{O} 35$ & 221 & 6 & 2 & 4 & 0.50 \\
\hline I56 & 257 & 1 & 3 & 6 & 0.50 \\
\hline Ave & 124 & 12 & 4 & 6 & 0.51 \\
\hline SD & 69 & 7 & 4 & 6 & 0.33 \\
\hline
\end{tabular}

The frequency of copulatory plug observations was unrelated to female age or dominance rank.

tory plug or not resulting in a plug. A total of 136 mating days were observed, with 71 of those mating days resulting in an observable copulatory plug and 65 resulting in no observable plug (table 2).

Pregnancy status (pregnant vs. non-pregnant) and trimester were determined after the end of the study by using birth records from the census database. We used dates of birth from the census database to backdate approximate dates of conception [Silk et al., 1993] to estimate pregnancy status during the study. Age was determined by consulting the census database; dominance rank was determined by birth age within matrilines and ad libitum dyadic agonistic interactions. At the beginning of the study, females were defined as non-parous if they had not yet had a live birth, and parous if they had given birth to at least 1 infant.

Digital photographs were opportunistically collected on a daily basis. Individual female colouration was measured following a protocol for the objective quantification of colour by Gerald et al. [2001]. After photos had been adjusted for varying light conditions, we used Adobe Photoshop 6.0 to measure three aspects of colour: hue, saturation and brightness. Hue refers to what we generally term as colour; saturation refers to the relative purity of colour, and brightness refers to the relative lightness of colour. Saturation and brightness values were measured as percentages; hue was measured in degrees, which was then scaled to match a $0-100$ scale.

It is important to note that our study is exploratory and has limitations. Our observations of copulatory plugs were potentially biased; only those plugs visible to the researchers were re- 
Table 2. Summary of observed mating days and observed copulatory plugs, sorted by pregnancy and parity status

\begin{tabular}{lllc}
\hline Pregnancy status & $\begin{array}{l}\text { Non- } \\
\text { pregnant }\end{array}$ & Pregnant & $\begin{array}{c}\text { Total days } \\
\text { sampled }\end{array}$ \\
\hline Days sampled & 552 & 667 & 1,219 \\
Mating days & 72 & 64 & 136 \\
Plug days & 50 & 27 & 77 \\
\hline Parity status & Nulliparous & Multi-/ & Total days \\
& & primiparous & sampled \\
\hline Days sampled & 318 & 901 & 1,219 \\
Mating days & 19 & 117 & 136 \\
Plug days & 12 & 65 & 77 \\
\hline
\end{tabular}

corded. We have no way of assessing how many plugs were missed; plugs may have been too small to be visible to the researcher [Parga, 2003] or may have been dislodged or removed without being observed and recorded. Additionally, we have occasionally observed females removing copulatory plugs, a behaviour also noted in Brachyteles [Strier, 1992] and Pan [Goodall, 1986].

Statistical analyses were performed using SPSS 16.0. Three rates related to mating and copulatory plug observation were calculated. Mating rate was calculated as total mating days over total days of observation. Raw rate of visible plugs (RVP) was calculated as total number of days with visible plugs over total number of observation days, and RVP was calculated as total days with a visible plug over total mating days. Binomial tests were performed on these rates to assess the significance of their differences when sorted by parity and pregnancy status. We performed one-way ANOVA tests to examine if observations of plugs were related to female age or dominance rank, and Pearson's correlation tests to determine if RVP was related to female age or dominance rank. We used paired t tests to compare female sexual skin colouration scores between plug and non-plug days to determine if intra-individual changes in genital colouration were related to plug observation.

\section{Results}

\section{Effect of Pregnancy Status on Copulatory Plugs}

Binomial tests were performed to assess if mating activity or copulatory plug observation was related to pregnancy status (table 3). When performing binomial tests on the calculated rates, we assumed non-pregnant rates to be the baseline. Nonpregnant females were observed to mate significantly more frequently, had significantly higher raw RVPs and significantly higher RVPs. The RVP measures the number of copulatory plug days per mating days and is especially important because it accounts for lower mating rates after conception.

\section{Effect of Parity Status on Copulatory Plugs}

Parity had a significant effect on both mating rate and raw RVP. Non-parous females were observed to mate less often and were observed with copulatory plugs 
Table 3. Impact of pregnancy and parity status on mating rates and raw rate of copulatory plug visibility

\begin{tabular}{lllll}
\hline Pregnancy status & Non-pregnant & Pregnant & Z score & Binomial significance, $p$ \\
\hline Mating rate & 0.1304 & 0.0959 & 2.6538 & 0.004 \\
Raw RVP & 0.0906 & 0.0404 & $\begin{array}{l}4.5225 \\
4.7409\end{array}$ & $<0.001$ \\
RVP & 0.6945 & 0.4219 & B.001 \\
\hline Parity status & Nulliparous & Parous & Z score & Binomial significance, p \\
\hline Mating rate & 0.0597 & 0.1299 & 3.7340 & $<0.001$ \\
Raw RVP & 0.0377 & 0.0721 & 2.3724 & 0.009 \\
RVP & 0.6316 & 0.5556 & 0.6672 & 0.252 \\
\hline
\end{tabular}

Pregnancy status had a significant impact on the rate of visible copulatory plugs, but parity status did not.

less often than parous females (table 3). The RVPs were not significantly different between non-parous and parous females. The significant difference in raw RVP may be an artefact of the disparate mating rates.

\section{Effect of Age and Rank on Copulatory Plugs}

We also performed one-way ANOVA tests to examine the potential effects of age and dominance rank on the distribution of copulatory plugs. To examine age, we divided females into three groups: old age (162-257 months, $n=9)$, middle age (75161 months, $\mathrm{n}=6)$ and young age (24-74 months, $\mathrm{n}=6)$; all females classified as young were non-parous adolescents at the beginning of the study. Using this method, we found no relationship between age and copulatory plug observation $\left(\mathrm{F}_{2,136}=\right.$ $0.230, \mathrm{p}=0.79$ ). We also separated females into three dominance rank groups (high: $\mathrm{n}=7$, middle: $\mathrm{n}=8$, low: $\mathrm{n}=6$ ) based on dominance relationships between matrilines; dominance rank was not related to copulatory plug observation $\left(\mathrm{F}_{2,136}=2.024\right.$, $\mathrm{p}=0.135)$.

In addition to the ANOVA tests, we used Pearson's correlation tests to analyse the relationship between RVP and female dominance rank and age. To control for the possible effects of repeated measures for females that received a disproportionate number of matings or copulatory plugs, we calculated a RVP for each female. As with the ANOVA test, the correlation tests also indicate that copulatory plugs are not related to female age $(n=24, r=-0.05, p=0.82)$ or dominance $\operatorname{rank}(n=24, r=0.04$, $\mathrm{p}=0.84)$.

\section{Female Colouration and Copulatory Plugs}

To examine the question of female colouration and the RVP, we analysed coordinated colour and mating data collected from 10 multiparous females; only 5 females had colour data collected on both copulatory plug and non-copulatory plug days (table 4). For all analyses of female colour, we used an average of each female's colour scores across each condition (plug and non-plug) to control for repeated mea- 
Table 4. Summary of colour data

\begin{tabular}{|c|c|c|c|c|c|c|}
\hline \multirow{2}{*}{$\begin{array}{l}\text { Animal } \\
\text { ID }\end{array}$} & \multicolumn{2}{|c|}{ Ave. genital hue } & \multicolumn{2}{|c|}{ Ave. genital saturation } & \multicolumn{2}{|c|}{ Ave. genital brightness } \\
\hline & non-plug & plug & non-plug & plug & non-plug & plug \\
\hline $42 \mathrm{~A}$ & 31 & 40 & 64 & 78 & 63 & 62 \\
\hline I56 & 34 & 33 & 79 & 98 & 53 & 43 \\
\hline T84 & 34 & 50 & 78 & 83 & 60 & 59 \\
\hline $36 \mathrm{D}$ & 35 & 40 & 67 & 71 & 57 & 53 \\
\hline $30 \mathrm{~F}$ & 33 & 52 & 67 & 89 & 61 & 51 \\
\hline Z82 & 35 & 37 & 61 & 75 & 68 & 61 \\
\hline
\end{tabular}

Ave. = Average. Genital hue and saturation are significantly higher on days when females were observed with copulatory plugs than on days when females were not observed with copulatory plugs. Genital brightness was significantly lower on copulatory plug days than non-copulatory plug days.

sures. Using paired t tests, we found that components of genital colouration were significantly higher on days when females were observed with copulatory plugs (hue: d.f. $=5, \mathrm{t}=-2.59, \mathrm{p}=0.05$; saturation: d.f. $=5, \mathrm{t}=-4.38, \mathrm{p}=0.01$ ), and genital brightness was significantly lower when females were observed with copulatory plugs (d.f. $=5, \mathrm{t}=3.26, \mathrm{p}=0.02$ ). This means that over the course of the mating season, females had more deeply reddened genital skin on the days that they were observed with a copulatory plug.

\section{Discussion}

Seminal coagulation and plug formation are the result of male physiology with the seminal vesicles and prostate controlling ejaculate volume and the prostate coagulation properties [for a review, see Dixson, 1998]. Among rhesus monkeys, semen coagulates soon after both masturbation [pers. observation] and electro-ejaculation [Settlage and Hendrickx, 1974] in the absence of physiological interactions with the female reproductive tract. Assuming that male ejaculate should always form a coagulate or copulatory plug, we observed that plugs seemed unevenly distributed among females.

Results from our exploratory study indicate that pregnancy affects the visibility or formation of copulatory plugs. Rhesus females are known to continue mating while pregnant, although male ejaculations significantly decreased and eventually ceased as pregnancy progressed [Bielert et al., 1976]. Similarly, in a field study of yellow baboons, Hausfater [1975] noted that only cycling females were observed with seminal coagulate. Our results suggest that once pregnant, females do significantly decrease mating activity, but even with consideration of mating rates, they are observed with significantly fewer visible copulatory plugs through the remainder of the mating season.

A potential explanation for these results is that males may invest less in copulatory plugs, possibly by decreasing ejaculate volume when females are pregnant. Par- 
ga et al. [2006] found significant inter- and intra-individual variation in copulatory plugs, suggesting that Lemur catta males exhibit considerable variation in ejaculate volume and copulatory plug formation. Experimental work by Settlage and Hendrickx [1974] found that in rhesus males, the most sperm-rich liquid portion of the ejaculate is expelled into the vagina first, before the coagulate portion of the ejaculate. They suggest that the coagulate itself may aid in sperm transport by directly binding to the external opening of the cervix or by protecting the semen from vaginal secretions.

Although coagulation is a function of male physiology, we offer several additional hypotheses for why pregnancy status may change the observation of copulatory plugs. First, pregnancy may affect the visibility of copulatory plugs in a mechanical way. Second, it is possible that hormonal and other physiological changes within the female reproductive tract may prevent or deter copulatory plug formation; cervicovaginal chemistry is known to change across the menstrual cycle [Michael et al., 1975] and during pregnancy [Mauro et al., 1970]. Poiani [2006] suggests that the female reproductive tract and seminal fluid act as a co-evolved system; the female reproductive tract may be both enabled and inhibited by the various molecular components of seminal fluid. Hernandez-Lopez et al. [2008] found that among blackhanded spider monkeys, seminal fluid effectively changes vaginal chemistry, making the female reproductive tract more hospitable for sperm and therefore fertilization. As pregnancy advances, a large amount of cervical mucus blocks off the entrance to the cervix [Hafez and Jaszczak, 1972]. Fertility studies in humans have indicated that the interaction between cervical mucus and seminal fluid may be particularly important in fertilization [Schats et al, 1984; for a review, see Dixson, 1998]. We suggest that future research examines if males preferentially produce copulatory plugs in non-pregnant females by producing different seminal compositions or if hormonal changes during pregnancy may alter vaginal chemistry and therefore affect copulatory plug formation or visibility.

Our results also indicate that genital colouration is positively related to the RVP. Among rhesus monkeys, changes in genital colouration have been linked with different stages of the oestrous cycle and male interest [Czaja et al., 1975] as well as ovulation probability [Brent et al., 2008]. One potential explanation for this result is that sexual skin colour may have an impact on male arousal and, subsequently, their mating activity, ejaculate volume or ejaculate composition. Among rhesus monkeys, ejaculate volume shows marked seasonality and inter-individual variability [Zamboni et al., 1974] as well as intra-individual variability [Settlage and Hendrickx, 1974].

In multimale-multifemale societies, several female characteristics, such as sexual skin colour, may contribute to varying levels of male arousal [Dixson 1983, 1998]. Among rhesus monkeys, changes in female sexual skin colour are related to the menstrual cycle [Czaja et al., 1975; Brent et al., 2008]. In this study, all components of genital colouration (hue, saturation and brightness) changed significantly on days when females were observed with a copulatory plug, whereas only one aspect of genital colouration, saturation, increased significantly on days when females were sexually active [Danzy and Gutierrez, unpubl. data]. It may be that genital saturation is affected by reproductive hormones in general, indicating that females are in oestros, whereas females that are more colourful in all three components of genital colouration are in a more specific part of the reproductive cycle, such as ovulation. Recent 
work by Brent et al. [2008] found that rhesus macaque females in the proceptive phase had a significantly higher genital hue and saturation, suggesting that components of genital colour may be linked with ovulation probability. If female sexual colouration influences male interest and therefore alters ejaculate volume or ejaculate composition, a higher RVP in some colourful, desirous rhesus females could be a result of a particular type of sexual interaction with males. Additionally, given that sexual skin colouration is linked with ovulation and the hormones that control reproductive cycling, it is possible that these hormones affect the chemical composition of the vaginal fluids potentially making the link between colouration of the sexual skin and the rate of copulatory plug visibility epiphenomenal. The visual interaction between copulatory plugs and sexual skin colour may play an important communicative role. The juxtaposition of opposing colours, a bright pink or red rump with a white plug may also be important [Henzi, 1985] and serve a communicative function in this species; copulatory plugs may communicate to conspecifics [J. Ayala, pers. comm.], specifically males, that females are in oestros or that females are consorting.

There are several important limitations to our work that should be considered for future studies of copulatory plugs among primates. First, mating rhesus monkeys can be aggressive, making observation of mating behaviour and copulatory plugs difficult. Second, copulatory plugs may not always be visible to the researcher, because of their size, depth or potential removal, therefore biasing observations. Among ring-tailed lemurs, copulatory plugs may be lodged deep within the reproductive tract and may not be observed until they become dislodged [Parga, 2003]; therefore, observational studies are limited to only quantifying those plugs which are immediately visible or later dislodged during focal-animal sampling.

Despite these caveats, we want to highlight that while copulatory plugs are generally thought of in terms of male physiology and male reproductive strategy, copulatory plugs may also be critically dependent on female reproductive status. These preliminary results suggest that further investigation of the distribution and physiological correlates of copulatory plugs is necessary for understanding the interaction of male and female reproductive strategies among rhesus monkeys.

\section{Acknowledgments}

We give a special thank you to Dr. M. Gerald, J. Ayala and the entire Cayo Santiago staff for their invaluable assistance to the researchers and excellent care of the monkeys. We thank Drs. M. McCrossin, B. Benefit and T. Wright at New Mexico State University (NMSU) for review of various parts of this project, and B. Cramer, M. Banegas and A. Lujan for assistance with data collection in the field. We also thank two anonymous reviewers for their helpful comments and suggestions for improving the manuscript.

Cayo Santiago is supported by Grant No. CM-5-P40RR003640-13 from the National Center for Research Resources (NCRR), a component of the National Institutes of Health (NIH). The contents of this paper are solely the responsibility of the authors and do not necessarily represent the official views of the NCRR or NIH. Funding for this project was provided by the NMSU Sociology-Anthropology Graduate Student Organization, the NMSU College of Arts and Sciences, and the Associated Students of NMSU. This research was approved by the Institutional Animal Care and Use Committees of the University of Puerto Rico and NMSU. 


\section{References}

Altmann J (1974). Observational study of behavior: sampling methods. Behavior 49: 227-267.

Altmann SA (1962). A field study of the sociobiology of rhesus monkeys, Macaca mulatta. Annals of the New York Academy of Sciences 102: 338-435.

Berard J (1999). A four-year study of the association between male dominance rank, residency status, and reproductive activity in rhesus macaques (Macaca mulatta). Primates 40: 159-175.

Bielert C, Czaja JA, Eisele S, Scheffler G, Robinson JA, Goy RW (1976). Mating in the rhesus monkey (Macaca mulatta) after conception and its relationship to oestradiol and progesterone levels throughout pregnancy. Journal of Reproduction and Fertility 46: 179-187.

Brent LJN, Dubuc C, Accamando AK, Engelhardt A, Heistermann M, MacLarnon A, Semple S, Gerald MS (2008). Does colour change signal the timing of ovulation in female rhesus macaques? Primate Eye 96: 338.

Carpenter CR (1942). Sexual behavior of free ranging rhesus monkeys (Macaca mulatta): specimens, procedures and behavioral characteristics of estrus. Journal of Comparative Psychology 3: 113142.

Czaja JA, Eisele SG, Goy RW (1975). Cyclical changes in the sexual skin of female rhesus: relationships to mating behavior and successful artificial insemination. Federation Proceedings 34: 16801684 .

Danzy JL (2007). The Color of Temperament and Heart: The Hormonal and Behavioral Basis of Female Rhesus Macaque Color on Cayo Santiago. MA thesis, New Mexico State University, Las Cruces.

Dixson AF (1983). Observations on the evolution and behavioral significance of 'sexual skin' in female primates. Advances in the Study of Behavior 13: 63-106.

Dixson AF (1998). Primate Sexuality: Comparative Studies of the Prosimians, Monkeys, Apes and Human Beings. Oxford, Oxford University Press.

Dixson AF, Anderson MJ (2002). Sexual selection, seminal coagulation and copulatory plug formation in primates. Folia Primatologica 73: 63-69.

- Gerald MS, Bernstein J, Hinkson R, Forbusy R (2001). A formal method for objective assessment of primate color. American Journal of Primatology 53: 79-85.

Goodall J (1986). The Chimpanzees of Gombe: Patterns of Behavior. Cambridge, Harvard University Press.

Hafez ESE, Jaszczak S (1972). Comparative anatomy and histology of the cervix uteri in non-human primates. Primates 13: 297-316.

Harcourt AH, Harvey PH, Larson SG, Short RV (1981). Testis weight, body weight and breeding system in primates. Nature 293: 55-57.

Hausfater G (1975). Dominance and Reproduction in Baboons (Papio cynocephalus): A Quantitative Analysis. Contribution to Primatology, vol. 7. Basel, Karger.

Henzi SP (1985). Genital signalling and the coexistence of male vervet monkeys (Cercopithecus aethiops pygerythrus). Folia Primatologica 45:129-147.

Hernandez-Lopez L, Cerda-Molina AL, Paez-Ponce DL, Mondragon-Ceballos R (2008). The seminal coagulum favours passage of fast-moving sperm into the uterus in the black-handed spider monkey. Reproduction 136: 411-421.

Mauro J, Serrone D, Somsin P, Stein AA (1970). Cyclic vaginal cytologic patterns in the Macaca mulatta. Acta Cytologica 14: 348-352.

Michael RP, Bonsall RW, Kutner M (1975). Volatile fatty acids, 'copulins', in human vaginal secretions. Psychoneuroendocrinology 1: 153-163.

Muehlenbein MP, Campbell BC, Murchison MA, Phillippi KM (2002). Morphological and hormonal parameters in two species of macaques: Impact of seasonal breeding. American Journal of Physical Anthropology 117: 218-227.

- Parga JA (2003). Copulatory plug displacement evidences sperm competition in Lemur catta. International Journal of Primatology 24: 889-899.

- Parga JA, Maga M, Overdorff DJ (2006). High-resolution X-ray computed tomography scanning of primate copulatory plugs. American Journal of Physical Anthropology 129: 567-576.

Poiani A (2006). Complexity of seminal fluid: a review. Behavioral Ecology and Sociobiology 60: 289310.

Rawlins RG, Kessler MJ (1986). The history of the Cayo Santiago colony. In The Cayo Santiago Macaques: History, Behavior, and Biology (Rawlins RG, Kessler MJ, eds.), pp 13-45. Albany, State University of New York Press.

Schats R, Aitken RJ, Templeton AA, Djahanbakhch O (1984). The role of cervical mucus-semen interaction in infertility of unknown aetiology. BJOG An International Journal of Obstetrics and Gynecology 91: 371-376. 
Settlage DSF, Hendrickx AG (1974). Observations on coagulum characteristics of the rhesus monkey electroejaculate. Biology of Reproduction 11: 619-623.

- Silk J, Short J, Roberts J, Kusnitz J (1993). Gestation length in rhesus macaques (Macaca mulatta). International Journal of Primatology 14: 95-104.

Strier KB (1992). Faces in the Forest: The Endangered Muriqui Monkeys of Brazil. Oxford, Oxford University Press.

Voss R (1979). Male accessory glands and the evolution of copulatory plugs in rodents. Occasional Papers of the Museum of Zoology-University of Michigan 689: 1-27.

Zamboni L, Conaway CH, Van Pelt L (1974). Seasonal changes in production of semen in free-ranging rhesus monkeys. Biology of Reproduction 11: 251-267. 